\title{
How important is a history of chest pain in determining the degree of ischaemia in patients with angina pectoris?
}

\author{
ARSHED A QUYYUMI, CHRISTINE M WRIGHT, LORNA J MOCKUS, KIM M FOX
}

From the National Heart Hospital, London

SUMMARY Since therapeutic decisions in patients with angina pectoris are usually based on the reported frequency of exertional and rest pain the relations between the historical frequency of chest pain and objective evidence of myocardial ischaemia during normal daily activity were investigated in 100 patients by 48 hour ambulatory ST segment monitoring. Of these 100 consecutive patients with chest pain, 91 had typical pain and nine some atypical features. Twenty six patients had normal coronary arteries and 52 of the 74 with significant coronary disease had ambulatory ST segment changes. There was no relation between the frequency of reported exertional or rest pain and $(a)$ the severity of coronary artery disease or $(b)$ the frequency of daytime or nocturnal ST segment changes. Twelve patients had nocturnal ST segment changes but only four complained of nocturnal angina. Most patients had both painful and painless episodes of ST segment changes, but a substantial number had either painless or painful episodes only. These differences were not related to the severity of coronary artery disease. Chest pain after the onset of ST segment change was perceived with wide interpatient and intrapatient variability.

Thus the frequency of pain is a poor indicator of the frequency of significant cardiac ischaemia. Individual differences in the perception of pain may be more important.

One of the earliest descriptions of the clinical syndrome of angina pectoris was by Heberden in 1772.1 Later, pathological studies showed the frequent association between angina pectoris and obstructive coronary artery disease. ${ }^{2}$ More recent studies, however, have underlined the poor correlation between the frequency and distribution of anginal chest pain and the severity of underlying coronary artery disease. ${ }^{3-6}$ Although these studies compared the subjective symptoms of chest pain with the anatomical features of the coronary arteries, no correlations have been found between the frequency of chest pain and objective indices of myocardial ischaemia in patients with varying severity of coronary artery disease.

Reversible changes in the ST segment have been shown to coincide with periods of myocardial ischaemia, but these may or may not be accompanied by anginal pain in patients with or without underlying obstructive coronary artery disease. ${ }^{78}$ Recent

Requests for reprints to Dr Arshed A Quyyumi, National Heart Hospital, Westmoreland Street, London W1M 8BA.

Accepted for publication 19 March 1985 improvements in ambulatory electrocardiographic recording systems have enabled us to observe changes in the ST segment during the patient's normal daily activities. ${ }^{9}$ The relation between the occurrence of chest pain and the appearance of myocardial ischaemia (ST segment shifts) in patients with varying severity of coronary artery disease can thus be studied.

This study was designed to investigate the relation between the historical frequency of chest pain and myocardial ischaemia as determined by ambulatory electrocardiographic ST segment monitoring.

\section{Patients and methods}

STUDY POPULATION

One hundred consecutive patients (74 men, 26 women; mean (SD) age, 53.2(9) years) referred to one consultant cardiologist at this hospital and undergoing diagnostic coronary arteriography for chest pain were investigated. Patients with severe conduction defects or gross left ventricular hypertrophy on the electrocardiogram, atrial fibrillation, severe valvar heart 
disease, and taking digoxin were excluded. Evidence of an old transmural myocardial infarction with electrocardiographic $Q$ waves was present in 27 patients, and there were resting ST-T wave changes in a further 21. Informed consent was obtained from every patient.

\section{CHEST PAIN}

All patients complained of chest pain. Important features in the patients' history were particularly noted.

Typical angina pectoris denoted pain anywhere in the chest with or without radiation, occurring on exertion and relieved promptly with rest or sublingual nitrates. The pain was often associated with other precipitating factors and sometimes occurred also at rest during the day.

Atypical angina pectoris denoted pain that was suggestive of myocardial ischaemia but had some atypical features.

Resting or nocturnal angina pectoris or both denoted typical anginal chest pain occurring not only during exertion but also at rest during the day or wakening the patient at night.

\section{STUDY PROTOCOL}

After hospital admission all antianginal medication was withdrawn 48 hours before further investigations were started. Glyceryl trinitrate was given for chest pain. Unless the patient complained of chest pain with minimal activity, he was encouraged to be mobile inside and outside the hospital. Ambulatory electrocardiographic ST segment monitoring was performed for $\mathbf{4 8}$ hours, during which time the patients kept angina diaries. They noted the time of onset of chest pain and the activity at the time of pain during the period of ambulatory monitoring.
AMBULATORY MONITORING

A two channel recording was obtained using two pairs of bipolar electrodes which were applied precordially to record lead CM5 in the first channel. Inferior changes were recorded in the second channel using a lead resembling aVF in 35 patients and a lead resembling lead II in the other 65. A 48 hour two channel recording was obtained on magnetic tape using a frequency modulated recorder (Oxford Medilog 2, frequency response $0.05-40 \mathrm{~Hz}$ ). The tapes were then visually analysed at 60 times normal speed (Oxford Medilog MA20 scanner), and areas of interest were printed out at $25 \mathrm{~mm} / \mathrm{s}$.

Significant ST segment depression was defined as planar or downsloping shift of the ST segment of $\geqslant 1$ $\mathrm{mm}$ in magnitude $0.08 \mathrm{~s}$ after the J point. Significant ST segment elevation was defined as an upward shift of the ST segment of $\geqslant 1 \mathrm{~mm}$ in magnitude at the J point.

\section{ANGIOGRAPHY}

Conventional contrast left venticulography and coronary arteriography were performed and a significant lesion was defined as a $\geqslant 70 \%$ luminal narrowing in a major coronary artery. Left main stem stenosis was classed as two vessel disease. Five patients with normal coronary arteries and ambulatory ST segment changes had ergonovine provocation, in which a mean dose of $0.6 \mathrm{mg}$ was given intravenously and the angiograms were repeated.

\section{Results}

Of the 100 patients, 26 had normal coronary arteries, 22 single vessel disease, 22 two vessel disease, and 30 three vessel disease. Seven patients had left main stem

Table 1 Subjective frequency of exertional and rest pain in patients with varying severity of coronary artery disease. Figures are numbers (\%) of patients

\begin{tabular}{|c|c|c|c|c|c|}
\hline \multirow[t]{2}{*}{ Coronary disease } & \multirow[t]{2}{*}{ No of patients } & \multicolumn{4}{|c|}{ Number of episodes: } \\
\hline & & $>1 / d a y$ & $<1 /$ day to $>1 /$ week & $<1 /$ week & None \\
\hline \multicolumn{6}{|c|}{ Exertional pain } \\
\hline $\begin{array}{l}0 \\
1 \\
2 \\
3 \\
\text { Left main stem }\end{array}$ & $\begin{array}{l}26 \\
22 \\
22 \\
30\end{array}$ & $\begin{array}{r}8(31) \\
10(45) \\
9(41) \\
18(60)\end{array}$ & $\begin{array}{l}5(19) \\
5(23) \\
4(18) \\
5(17)\end{array}$ & $\begin{array}{r}13(50) \\
7(32) \\
9(41) \\
7(23)\end{array}$ & $\begin{array}{l}0(0) \\
0(0) \\
0(0) \\
0(0)\end{array}$ \\
\hline stenosis ${ }^{\star}$ & 7 & $7(100)$ & $\begin{array}{l}0(0) \\
t \text { rest }\end{array}$ & $0(0)$ & $0(0)$ \\
\hline $\begin{array}{l}\text { No of vessels affected: } \\
0 \\
1 \\
2 \\
3 \\
\text { Left main stem }\end{array}$ & $\begin{array}{l}26 \\
22 \\
22 \\
30\end{array}$ & $\begin{array}{l}4(15) \\
6(28) \\
3(14) \\
6(20)\end{array}$ & $\begin{array}{l}4(15) \\
2(9) \\
4(18) \\
2(7)\end{array}$ & $\begin{array}{r}17(65) \\
8(36) \\
7(32) \\
8(27)\end{array}$ & $\begin{array}{r}2(5) \\
6(28) \\
8(36) \\
14(46)\end{array}$ \\
\hline stenosis & 7 & $2(29)$ & $1(13)$ & $2(29)$ & $2(29)$ \\
\hline
\end{tabular}

^These patients are also included in the figures for two and three vessel disease. 
Table 2 Subjective frequency of exertional and rest pain in patients with coromary artery disease and episodes of ST segment change (during daytime only and during daytime and at night) and in patients with no ST segment change. Figures are numbers (\%) of patients

\begin{tabular}{|c|c|c|c|c|c|}
\hline \multirow[t]{2}{*}{$S T$ segment changes } & \multirow[t]{2}{*}{ No of patients } & \multicolumn{4}{|c|}{ Number of episodes: } \\
\hline & & $>1 /$ day & $<1 /$ day to $>1 /$ week & $<1 /$ week & None \\
\hline $\begin{array}{l}\text { Daytime only } \\
\text { Nocturnal and daytime } \\
\text { None }\end{array}$ & $\begin{array}{r}41 \\
111 \\
22\end{array}$ & $\begin{array}{r}22(54) \\
6(55) \\
9(40)\end{array}$ & $\begin{array}{c}\text { al pain } \\
4(10) \\
3(27) \\
7(33) \\
\text { ain }\end{array}$ & $\begin{array}{r}15(36) \\
2(18) \\
6(27)\end{array}$ & $\begin{array}{l}0(0) \\
0(0) \\
0(0)\end{array}$ \\
\hline $\begin{array}{l}\text { Daytime only } \\
\text { Nocturnal and daytime } \\
\text { None }\end{array}$ & $\begin{array}{r}41 \\
11 \\
22\end{array}$ & $\begin{array}{l}5(12) \\
3(28) \\
4(18)\end{array}$ & $\begin{array}{l}6(15) \\
0(0) \\
3(13)\end{array}$ & $\begin{array}{r}15(37) \\
4(36) \\
8(38)\end{array}$ & $\begin{array}{r}15(36) \\
4(36) \\
7(31)\end{array}$ \\
\hline
\end{tabular}

stenosis. Ninety one patients complained of typical anginal pain and nine had atypical features. One patient with atypical chest pain had normal coronary arteries but the other eight had significant coronary artery disease.

Patients complained of pain of varying severity and type (Table 1). All suffered chest pain durng exertion in the daytime, $70 \%$ also complained of rest pain of varying frequency, and $39 \%$ complained of nocturnal angina.

\section{RELATION BETWEEN PAIN AND THE SEVERITY OF} CORONARY ARTERY DISEASE

There was no correlation between the frequency of exertional or rest angina and the underlying coronary anatomy (Table 1). Thus $60 \%$ of patients with three vessel disease complained of frequent $(>1$ episode a day) exertional pain, and $31 \%$ of patients with normal coronary arteries also had frequent exertional pain. Similarly, frequent ( $>1$ episode a day) rest pain occurred in $20 \%$ of patients with three vessel disease and also in $15 \%$ of patients with normal coronary arteries. All seven patients with left main stem stenosis complained of frequent exertional pain.

\section{RELATION BETWEEN PAIN AND AMBULATORY ST} SEGMENT CHANGE

Fifty one of the $74(69 \%)$ patients with coronary artery disease had episodes of transient ST segment depression and one had episodes of ST segment elevation and depression during 48 hours of ambulatory monitoring (Table 2). ST segment changes occurred during the daytime on exertion in all 52 patients with ambulatory ST segment changes, and nocturnal resting ST segment changes occurred in $11(15 \%)$ of patients with coronary artery disease.

Table 2 compares the historical frequency of exertional and rest pain with the frequency of ambulatory daytime (exertional) and nocturnal (resting) ST segment changes. There was no correlation between the frequency of exertional or of rest pain and the frequency of observed daytime or nocturnal ST segment changes. Thus a history of frequent $(>1$ episode a day) exertional angina was obtained not only from $54 \%$ of patients with ambulatory ST segment changes but also from $40 \%$ of patients with no ambulatory ST segment changes after 48 hours of monitoring. Similarly, a history of infrequent ( $<1$ episode a week) chest pain was obtained from $33 \%$ of patients who had ambulatory ST segment changes during $\mathbf{4 8}$ hours of monitoring. Almost $90 \%$ of 39 patients with varying frequency of nocturnal angina pectoris had no nocturnal ST segment changes during 48 hours of monitoring. When the historical frequency of rest pain was analysed, $75 \%$ of patients with frequent $(>1$ episode a day) pain had no nocturnal resting ST seg-

Table 3 Frequency of painful and painless episodes of ST segment change in patients with varying severity of coronary artery disease

\begin{tabular}{|c|c|c|c|c|c|}
\hline \multirow[t]{2}{*}{ Coronary artery disease } & \multirow[t]{2}{*}{ No of patients } & \multirow[t]{2}{*}{$\%$ Of painful episodes } & \multicolumn{3}{|c|}{ Number of patients: } \\
\hline & & & $\begin{array}{l}\text { With painful and } \\
\text { painless episodes }\end{array}$ & $\begin{array}{l}\text { With painful episodes } \\
\text { only }\end{array}$ & $\begin{array}{l}\text { With painless episodes } \\
\text { only }\end{array}$ \\
\hline \multirow{3}{*}{$\begin{array}{l}\text { Normal } \\
\text { Spasm only } \\
\text { No of vessels affected: } \\
1 \\
2 \\
3 \\
\text { Left main stem } \\
\text { stenosis` }\end{array}$} & $\begin{array}{l}5 \\
1\end{array}$ & $\begin{array}{r}8 \\
39\end{array}$ & $\begin{array}{l}1 \\
1\end{array}$ & $\begin{array}{l}0 \\
0\end{array}$ & $\begin{array}{l}4 \\
0\end{array}$ \\
\hline & $\begin{array}{l}11 \\
17 \\
24\end{array}$ & $\begin{array}{l}31 \\
48 \\
29\end{array}$ & $\begin{array}{r}5 \\
5 \\
14\end{array}$ & $\begin{array}{l}4 \\
4 \\
6\end{array}$ & $\begin{array}{l}2 \\
8 \\
4\end{array}$ \\
\hline & 7 & 36 & 6 & 0 & 1 \\
\hline
\end{tabular}

$\star^{\star}$ These patients are also included in the figures for two and three vessel disease. 
Table 4 Comparison between the frequency, duration, and magnizude of painful and painless ST segment change in 24 patients with coronary artery disease and episodes of both painful and painless $S T$ segment change. Values are mean $(S D)$

\begin{tabular}{lcc}
\hline & Painful & Painless \\
\hline No of episodes & $4 \cdot 3(4 \cdot 7)$ & $5 \cdot 9(4 \cdot 8)$ \\
Duration (mins) & $24 \cdot 5(31 \cdot 5)$ & $16(10)$ \\
Magnitude (mm) & $2 \cdot 1(1 \cdot 1)$ & $1 \cdot 6(0.8)$ \\
\hline
\end{tabular}

ment changes, whereas $36 \%$ of the patients with nocturnal ST segment changes complained of no rest pain (Table 2).

\section{ANALYSIS OF PAINFUL AND PAINFREE ST}

SEGMENT CHANGES

In 52 patients with coronary artery disease and ambulatory ST segment changes, a mean of $30 \%$ of all episodes of ST segment change recorded were associated with pain. In the five patients with normal coronary arteries and ambulatory ST segment depression, however, only one episode (8\%) was accompanied by pain (Table 3).

In patients with coronary artery disease, $27 \%$ of patients had painful episodes of ST segment change only, $27 \%$ of patients had painfree episodes of ST segment change only, and $46 \%$ had both painful and painless episodes of ST segment change during monitoring. Nevertheless, there was no significant difference between the occurrence of painful or painfree episodes and the severity of underlying coronary artery disease (Table 3 ).

The characteristics of painful episodes of ST segment changes were compared with the painfree episodes in 24 patients who had both types of episodes during monitoring (Table 4). Painful episodes of ST segment change tended to be longer in duration and greater in magnitude than painless episodes, although these differences were not statistically significant.

\section{ACTIVITY ANALYSIS}

The activity at the time of chest pain was recorded by the 37 patients who also had ST segment changes on the electrocardiogram. Whereas $63 \%$ of these episodes were recorded as occurring during activities such as walking, shaving, or eating, $37 \%$ of the episodes occurred at rest during the day or at night. Chest pain was reported to occur a mean (SD) of $11(18)$ mins after the first onset of ST segment change, ranging from the time coinciding immediately with the onset of ST segment depression to 48 minutes after the onset of ST segment change. There was a wide intrapatient and interpatient variability in the time of onset of ST segment change on the electrocardiogram and the perception of chest pain.

\section{Discussion}

The patient's history of typical anginal chest pain is still regarded as one of the most sensitive indicators of the likelihood of the presence of significant coronary artery disease. ${ }^{10} \mathrm{It}$ is, however, possible for myocardial ischaemia and true angina pectoris to occur in this group of patients as a result of localised coronary artery spasm, ${ }^{11}$ which could be found in one of the six patients who had ambulatory ST segment changes. Two important points emerged from analysing this consecutive series of patients. Firstly, the clinical history of the type of frequency of chest pain was insufficient to identify the severity of underlying coronary artery disease (Tables 1-3). Secondly, ambulatory ST segment monitoring but not the history was able to identify the patient who had normal coronary arteries and coronary spasm.

Chest pain suggesting myocardial ischaemia can occur as a result of several non-cardiac conditions, and these may have been the cause in the vast majority of patients with normal coronary arteries. Nevertheless, $27 \%$ of patients with significant coronary artery disease also developed chest pain that was not associated with objective evidence of myocardial ischaemia (ST segment depression). A greater proportion of these patients, however, had episodes of ST segment change at other times associated with "similar" bouts of pain. These factors underline the difficulties of ascribing similar degrees of ischaemia to all episodes of pain complained of by the patient, as some episodes were associated with pronounced ST segment changes and others resulted in no change in the electrocardiogram. Although shifts in the ST segment of $\geqslant 1 \mathrm{~mm}$ in magnitude only were regarded as significant for ischaemia, care was taken to analyse the electrocardiogram when the patients complained of chest pain, and almost invariably no changes in the ST segment or $T$ waves were observed.

Exertional angina is often treated with beta adrenoreceptor antagonists, which reduce myocardial oxygen demand at a given workload, 12 but ischaemia at rest is often treated with vasodilators. 1314 These therapeutic decisions in clinical practice are often based on the patient's history and factors precipitating pain. This study highlights the unreliability of the history in determining the extent and frequency of myocardial ischaemia during the day or at rest at night as this may lead to either overestimation or underestimation of the ischaemia.

Usually, the subjective frequency of chest pain underestimated the frequency of myocardial ischaemia ${ }^{15}$ in patients in whom ST segment changes were recorded. In fact, 14 patients had painfree episodes only. The reason why pain occurs with one episode of ST segment change and not another in the 
same patient is still not fully understood. There is a suggestion from this series of patients and other reports ${ }^{15}$ that painful ischaemia is more profound in terms of either the size of myocardium involved or the duration of ischaemia. The perception of chest pain from the time of onset of the first change in the ST segment showed a considerable variation in the same patient and between individual patients. It is clear, therefore, that the occurrence of chest pain with ischaemia is dependent on individual factors as well as on the magnitude of underlying ischaemia. ${ }^{15} 16$

Prognostic information is not as yet available for patients who have multiple episodes of painful and painless ST segment changes during normal daily activities, ${ }^{17}$ and long term studies are necessary to investigate the significance of asymptomatic myocardial ischaemia.

We thank the British Heart Foundation for their support.

\section{References}

1 Heberden W. Some account of a disorder of the breast. Medical Transactions 1772; 2: 59-67.

2 Herrick JB, Nuzum FR. Angina pectoris. JAMA 1918; 70: 67-70.

3 Proudfit WL, Shirey EK, Sones FM Jr. Selective cine coronary arteriography. Correlation with clinical findings in 1000 patients. Circulation 1966; 33: 901-10.

4 Proudfit WL, Shirey EK, Sheldon WC, Sones FM Jr. Certain clinical characteristics correlated with extent of obstructive lesions demonstrated by elective cinecoronary arteriography. Circulation 1968; 38: 947-54.

5 Fuster V, Frye RL, Connolly DC, Danielson MA, Elveback LR, Kurland LT. Arteriographic patterns early in the onset of the coronary syndromes. Br Heart $\mathrm{f}$ 1975; 37: 1250-5.

6 Leaman DM, Brower RW, Meester GT, Serruys P, Van den Brand M. Coronary artery atherosclerosis: severity of the disease, severity of angina pectoris and compromised left ventricular function. Circulation 1981; 63: 28592.

7 Guazzi M, Polese A, Fiorentini C, Magrini F, Olivari MT, Bartorelli C. Left and right heart haemodynamics during spontaneous angina pectoris. $\mathrm{Br}$ Heart $\mathcal{F}$ 1975; 37: 401-13.

8 Chierchia S, Brunelli C, Simonetti I, Lazzari M, Maseri A. Sequence of events in angina at rest: primary reduction in coronary flow. Circulation 1980; 61: 759-68.

9 Bragg-Remschel DA, Anderson CM, Winkle RA. Frequency response characteristics of ambulatory ECG monitoring systems and their implications for ST segment analysis. Am Heart f 1982; 103: 20-31.

10 Diamond GA, Forrester JS. Analysis of probability as an aid in the clinical diagnosis of coronary artery disease. $N$ Engl f Med 1979; 300: 1350-8.

11 Maseri A, Severi S, De Nes M, et al. "Variant" angina: one aspect of a continuous spectrum of vasospastic myocardial ischemia. Am $\mathcal{F}$ Cardiol 1978; 42: 1019-35.

12 Thadani U, Davidson C, Singleton W, Taylor SH. Comparison of five beta-adrenoreceptor antagonists with different ancillary properties during sustained twice daily therapy in angina pectoris. Am $\mathcal{F}$ Med 1980; 68: 243-50.

13 Parodi O, Maseri A, Simonetti I. Management of unstable angina at rest by verapamil. $B r$ Heart $\mathcal{F} 1979 ; 41$ : 167-74.

14 Gerstenblith G, Ouyang P, Achuff SC, et al. Nifedipine in unstable angina: a double-blind, randomized-trial. $N$ Engl f Med 1982; 306: 885-9.

15 Cecchi AC, Dovellini EV, Marchi F, Pucci P, Santoro GM, Fazzini PF. Silent myocardial ischemia during ambulatory electrocardiographic monitoring in patients with effort angina. $\mathcal{F}$ Am Coll Cardiol 1983; 1: 934-9.

16 Droste C, Roskamm H. Experimental pain measurement in patients with asymptomatic myocardial ischemia. $f$ Am Coll Cardiol 1983; 1: 940-5.

17 Cohn PF. Prognosis and treatment of asymptomatic coronary artery disease. F Am Coll Cardiol 1983; 1: 959 64. 